\title{
COPD - PREVALENCE AND RISK STUDY AMONG FEMALES OF RURAL AREA, DISTRICT AMBALA, HARYANA, INDIA
}

Mukhmohit S1 ${ }^{1}$ Bhardwaj A2, Saini S33, A. K. Mukherjee ${ }^{4}$, Kannan R ${ }^{5}$

\section{HOW TO CITE THIS ARTICLE:}

Mukhmohit S, Bhardwaj A, Mukherjee A. K, Saini S, Kannan R. "COPD - Prevalence and Risk Study among Females of Rural Area, District Ambala, Haryana, India". Journal of Evolution of Medical and Dental Sciences 2014; Vol. 3, Issue 16, April 21; Page: 4183-4191, DOI: 10.14260/jemds/2014/2416

ABSTRACT: BACKGROUND: The increasing impact of COPD on health care resources is now being recognized as a major public health problem and is projected to be the third leading cause of death worldwide by 2020. Factually, the huge variability across our nation makes it pivotal to make epidemiological mapping and prevalence data be calculated and represented by different regions. This study was undertaken to assess the epidemiology of COPD among females from rural area of district Ambala, Haryana. MATERIAL AND METHODS: A community based, cross sectional study was conducted in 1027 females from the field practice area of Rural Training health centre located in village barara district Ambala, Haryana. The data was collected by interviewing the individuals by doing house to house visit by questionnaire based interview method, clinical examination and spirometry where necessary, after obtaining an informed and written consent. The data was statistically tested using Microsoft excel 2007, Epi Info 3.1.1 and SPSS version 17. RESULTS: The overall prevalence of COPD was observed as 5.1\%. On MLR analysis, age more than 50 years (OR 13.140; CI 5.64 - 23.095), low socio economic status (OR 3.11; CI 1.547-6.25), smoking (OR 6.187; CI $2.274-16.836$ ) and use of biomass as a source of fuel for cooking (OR 1.46; CI $1.087-3.248$ ) and kitchen smoke exposure for more than 30 years (OR 2.479; CI $1.414-4.374$ ) were found to be significantly associated with COPD. CONCLUSION: Kitchen fuel exposure and using biomass and coal as a fuel are strongly associated with development of COPD in rural females.

KEYWORDS: COPD, Education, Smoking, Indoor air pollution.

Abbreviations: COPD: Chronic Obstructive Pulmonary Disease, MLR: Multiple Logistic Regression, OR: Odd's Ratio, CI: Confidence Interval.

INTRODUCTION: Chronic obstructive pulmonary disease (COPD), which includes chronic bronchitis and emphysema, is a progressive disease characterized by airflow limitation/obstruction that is either not reversible at all or only partially reversible. It is generally difficult to separate out the two conditions (chronic bronchitis and emphysema); hence these are grouped together as COPD ${ }^{1}$. Although COPD is not curable, but it is a common treatable and preventable disease, and with adequate treatment the progression is slowed. ${ }^{2}$ Airflow obstruction is the basic culprit in COPD which further includes an array of contributory factors as airway inflammation, remodeling, bronchospasm, mucous hyper secretion and loss of elastic recoil.

Smoking is a greater cause of mortality and disability than any single disease. ${ }^{3}$ The evidence for causal relationship of cigarette smoking with COPD has been well established ${ }^{4}$ and worldwide cigarette smoking is the most common risk factor for COPD, although in many countries, air pollution resulting from the burning of wood and other biomass fuels has been identified as an additional risk factor for COPD. 5 The mortality fraction for COPD attributed to smoking ranged between $77-84 \%$ in males whereas in females it ranged between $61-62 \%^{6}$ 
The causes for COPD have opposite patterns according to the geographic areas. In high- and middle-income countries tobacco smoke is the biggest risk factor, meanwhile in lowincome countries exposure to indoor air pollution, such as the use of biomass fuels for cooking and heating, causes the COPD burden.7 Wood, coal and other forms of Biomass (animal dung, crop resides) are commonly used sources of energy in the developing countries ${ }^{8}$ and is estimated that more than $50 \%$ of the world population rely on these sources to meet their most basic energy needs. ${ }^{2}$ Exposure is particularly high among women and children, who spend the most time near the domestic hearth, in fact biomass smoke exposure occurs during entire lifespan. It begins in utero and continues during infancy, impairing lung defense mechanisms and increased chance of respiratory infections and tuberculosis and consequently impaired lung health and COPD ${ }^{9}$. Women exposed to indoor smoke are three times as likely to suffer from COPD, than women who cook and heat with gas and other cleaner fuels. COPD and women -- it's a combination that, until recent years, has not drawn much attention. Roughly 15\% of all people who are diagnosed with COPD have never smoked. Notably, out of this group, nearly $80 \%$ are women, suggesting that women may be more vulnerable to risk factors associated with COPD that are not related to smoking. ${ }^{10}$ The increase in prevalence of COPD among women has prompted much needed research that is ongoing and future-driven among the women in rural area of Haryana, India, using spirometry (according to GOLD criteria) as tool for diagnosis of COPD.

MATERIAL AND METHODS: It was a community based, cross sectional study to estimate the prevalence and study the risk factors implying in relation to chronic obstructive pulmonary disease in the female population. The study was conducted in the field practice area of Rural Training health centre located in village barara district Ambala, Haryana. As per survey report there were estimated 2500 females aged more than 35 years in the rural field practice area.

Sample Size: Keeping in view the review of literature, the prevalence of Chronic bronchitis ranged from $2 \%-4.9 \%{ }^{11}$ in females. Hence, considering an average prevalence of 5 per cent, an alpha error of 5 per cent, 1 per cent absolute allowable error, the sample size of 1055 was calculated for the study purpose by formula adopted from Epi Info version 3.5.1.

$$
\mathrm{S}=\mathrm{Z} * \mathrm{Z}(\mathrm{P}(1-\mathrm{P})) /(\mathrm{D} * \mathrm{D})
$$

Where, $\mathrm{D}$ is one half the width of the desired sample confidence interval.

$\mathrm{Z}$ is a percentile of the standard normal distribution (1.96 for $95 \%$ Confidence interval) determined by the specified confidence level. A total of 1055 females were interviewed but 28 females did not give consent for further examinations. However, 28 females were consequently dropped out at the stage of data compilation and thus 1027 females were interviewed and screened for COPD and assessed for risk factors for COPD.

Strategy: The sampling unit of the study was household and all the eligible persons in the household were included in the study. As per survey register from RTHC barara every 3rd house from each village was visited till the desired sample size for each village was achieved. The data was collected by interviewing the individuals by doing house to house visit. Those who were not available in the first visit were revisited on another day, preferably on holiday. For any house found 
permanently locked, the subsequent next available household was taken. The data collection was done by questionnaire based interview method, clinical examination and spirometry where necessary, after obtaining an informed and written consent.

This was a multiphasic study with various tests applied in two phases. Phase 1: All eligible individuals were screened for chronic obstructive pulmonary disease by interviewing as per the pretested, semi structured questionnaire. Physical assessment and anthropometric measurements were measured. Later, Peak flow rate was measured for all individuals under standard operating protocol. Phase 2: All individuals who were either identified as COPD by questionnaire based on clinical criteria: cough and phlegm $\geq 3$ months every year during $\geq 2$ consecutive years (chronic bronchitis) or PEF below the cutoff $<70 \%$ were subjected to pulmonary function test to check and to confirm for the diagnosis of Chronic obstructive pulmonary disease.

Study Tools: A single scientific definition of COPD as defined by GOI/WHO ${ }^{1}$ biennium GOLD staging criteria, considered as standard definition for diagnosing COPD in India was used.

Diagnosis of COPD was confirmed by assessment of both signs and symptoms of chronic bronchitis and/or pulmonary emphysema and functional criteria of chronic irreversible airflow obstruction (forced expiratory volume in one second (FEV1)/Forced vital capacity (FVC) less than $70 \%, \mathrm{FEV}_{1}$ less than $80 \%$ predicted) and without asthma as assessed by clinical history and response to bronchodilator (change less than $12 \%$ in $\mathrm{FEV}_{1}$ following $200 \mu \mathrm{g}$ inhaled salbutamol).

A pretested, semi structured, standardized and validated questionnaire ${ }^{12}$ was used which was however modified depending upon local needs. Interview method was adopted for extracting information for the questionnaire.

The respondents were asked about the general socio-demographic details (age, education, occupation, income), type of kitchen fuel used, environmental exposure, health related details, etc.

Data Analysis: The data was statistically tested using Microsoft excel 2007, Epi Info 3.1 .1 and SPSS version 17. The prevalence for COPD and other factors was calculated by proportions. For quantitative variables, as $\mathrm{PEF}, \mathrm{FEV}_{1}$ and $\mathrm{FVC}$ values descriptive statistics was used and the significance of association with COPD was assessed. For the assessment of qualitative attributes as risk factors, chi square test, univariate and multivariate logistic regressions analysis was done.

Ethical considerations: All participants were interviewed after obtaining an informed and written consent. All those who were diagnosed as COPD by GOLD criteria were referred to the rural training health centre or Primary health centre along with the spirometric findings.

RESULTS: The overall prevalence of COPD was observed as 5.1\%. Among the total 1027 females interviewed, 648 were in the age group of 35-50 years and among these $1.9 \%$ were diagnosed for COPD. An increasing trend of COPD was found with increasing age. The mean Spirometric parameters were found to be significantly lower for age category more than 65 years (for $\mathrm{FEV}_{1}$ $\mathrm{F}=12.363$, $\mathrm{p}$ value 0.00 and FEV1/FVC F=15.485, p value 0.00 ). However, FVC was not found to vary with the array of age distribution category. (Table-I)

Education and monthly family income were found to play a significant role in causing COPD. It was seen that more than half of the females were illiterate and among them $6.8 \%$ had COPD. On statistical analysis, the result was found to be significant thereby showing that education 
does affect the disease pattern ( $\mathrm{p}$ value $<0.05$ ). Females belonging to the families with a monthly income of less than $6000(\mathrm{~N}=196)$ were found to have statistically significantly higher COPD prevalence as compared to ones with a higher monthly family income of more than 6000 (Table-II). Although majority of the females were non-smokers (96.4\%), tobacco smoking was found to be significantly associated with COPD. The smoker females were found to have 7 times more risk of getting COPD than the non-smokers (Table-III). Most of females were found to have moderate exposure to kitchen smoke (40.5\%) while one third of the females $(33.1 \%)$ had heavy exposure to kitchen smoke. Lowest percentage of females (26.4\%) was found to have light exposure to kitchen smoke (Table III).

On MLR analysis, age more than 50 years (OR 13.140; CI 5.64 - 23.095), Lower income level (OR 3.11; CI 1.547 - 6.25), smoking status (OR 6.187; CI 2.274 - 16.836), use of biomass fuel (OR 1.46; CI 1.087 - 3.248) were found to be significantly associated with COPD. Females having their kitchen ill-ventilated and inside the living room were found to be at twice the odds of developing COPD as compared to ones having kitchen in an open area (Table IV). It was also observed that females with kitchen fuel exposure for more than 30 years were at a higher risk for development of COPD compared to those exposed for lesser years (OR 2.479; CI 1.414 - 4.374). Multivariate analysis using backward conditional method for logistic regression technique using variables as age, income, smoking, education, kitchen exposure years and location of kitchen was done. It was found that age, family income and smoking were the final variables in the equation which were found to be most significant for predicting COPD as the dependent variable.

DISCUSSION: The overall prevalence of COPD, 5.1\%, was found comparable with that estimated by Mahesh et al who reported an overall prevalence of COPD as $4.5 \%$ among the females ${ }^{12}$. This slight increase in the prevalence of COPD could be because of difference in the diagnostic criteria as well as difference in the age characteristics of the study participants.

Aging process has detrimental effects on lung along with derangements of pulmonary function parameters. These values may be further decreased in the presence of risk factors as smoking and dust exposure. Moreover, increasing age is also directly related to increasing levels of exposure to air pollution and henceforth lung damage. The results from the present study were similar to the COPD prevalence estimates by Menezes et al, PLATINO study, Brazil13 which showed a prevalence of $16.2 \%$ for age $50-60$ years and $25.7 \%$ for age more than 60 years. The association between low education levels and COPD was found to be statistically significant $\left(\chi^{2}\right.$ 7.87; $\mathrm{p}=0.005)$. The inverse relation of lower educational status and higher COPD was found to be similar with the results by Menezes et al ${ }^{13}$ who reported a higher COPD prevalence $(22.1 \%)$ among individuals having 0-2 years of formal education followed by $10.4 \%$ among those having more than 9 years of formal education.

Low socio economic status owing to low monthly family income as a risk factor for COPD is possibly attributable to the effects of indoor air pollution from cooking in ill ventilated kitchens of small and sometimes single room houses. Other possible factors could be smoking of crude forms of tobacco (beedi smoking) and malnutrition owing to lower financial condition. Similar results were reported by Jindal et $\mathrm{al}^{14}$ as higher prevalence of COPD in low SES (6.6\%) followed by medium SES (4.3\%) and lowest in high SES (3.6\%). 
The odds of COPD among the ever smoker females was observed as more than 7 times as that of never smoker females (OR 7.35; 95\% CI 3.25 - 16.6) in the present study. This observation implies that for development of COPD, smoking and female gender probably have a synergistic effect, rather than an additive effect. This could be explained on the basis of cumulative effect of kitchen smoke, housing conditions and general health status along with smoking habits. The results are supported by the Copenhagen centre for prospective studies, Prescott et al15, revealing OR 2.96 (CI 1.8-4.87) versus 1.39 (0.77-2.51) for mortality due to respiratory diseases in females compared to males.

Regarding location of the kitchen, a higher risk of COPD was observed among the females having kitchen located inside the living room as compared to the ones having kitchen outside the living room. The possible reason for the kitchen smoke exposure as risk factor for development of COPD could be related to the type of fuel used in the kitchen. Biomass (wood, animal dung, and crop residues), when used as a fuel emits high levels of multiple pollutants that are similar to those present in tobacco smoke and points towards the fact that kitchen smoke exposure is a risk factor for development of COPD. Similar findings were also reported from study by Behera et al ${ }^{16}$ and they showed that chronic bronchitis is significantly higher in wood/cow dung users than that in kerosene or LPG users. Indoor air pollution from biomass smoke is the most direct physical health risk especially to the females who spend most of their time in the kitchen cooking food. Increase in the prevalence of COPD with increasing age has been found to be similar to the results of earlier reports 17 in female subjects from Gujjar, a rural area in the Kashmir valley.

The association of indoor air pollution from domestic fuel combustion, in view of poorly ventilated houses in rural areas and development of COPD has been reported from India, Nepal, Mexico and China and is considered an important non-smoking risk factor especially for developing countries. ${ }^{18}$

CONCLUSION: The background risk of COPD exists with incremental age and smoking and on the basis of the present study; there is evidence of illiteracy, low socio economic status, exposure to biomass smoke as novel risk factors which play vital role in burden of COPD among females, especially non-smokers. The present study adds to the data available from the region of district Ambala, India and establishes the risk factors which are associated with higher risks for development of COPD in regard to the female subset of the population.

\section{REFERENCES:}

1. Jindal SK, Gupta D, Aggarwal AN. Guidelines for Management of Chronic Obstructive Pulmonary Disease (COPD) in India: A Guide for Physicians (2003). Indian J Chest Dis Allied Sci 2004; 46: 137-53.

2. Chronic Obstructive Pulmonary Disease (COPD)- Fact Sheet [Internet] [Accessed on July 19, 2011). Available from URL: http://www.who.int/mediacentre/factsheets/fs315/en/index.html

3. Smoking and your health. British Broadcasting Company [Internet] 2011 [Accessed on October $3,2011]$. Available from URL: http://www.bbc.co.uk/health/physical_health/conditions/smoking_health_effects.html 
4. Chan-Yeung M, Ait-Khaled N, White N, Ip MS, Tan WC. The burden and impact of COPD in Asia and Africa. Int J Tuberc Lung Dis. 2004 Jan; 8(1): 2-14.

5. Osaka D, Shibata Y, Abe S, Inoue S, Tokairin Y, Igarashi A et al. Relationship between habit of cigarette smoking and airflow limitation in healthy Japanese individuals: the Takahata study. Intern Med. 2010; 49(15): 1489-99.

6. Zielinski J, Bednarek M, Górecka D, Viegi G, Hurd SS, Fukuchi Y et al. Increasing COPD awareness. Eur Respir J. 2006 Apr; 27(4): 833-52.

7. World Health Organization. Causes of COPD [Internet] 2011 [Accessed on 19 July 2011]. Available from URL: http://www.who.int/respiratory/copd/causes/en/index.html

8. Hu G, Zhou Y, Tian J, Yao W, Li J, Li B, Ran P. Risk of COPD from exposure to biomass smoke: a meta-analysis. Chest 2010 Jul; 138(1): 20-31.

9. Eisner MD, Anthonisen N, Coultas D, Kuenzli N, Perez-Padilla R, Postma D et al. An Official American Thoracic Society Public Policy Statement: Novel Risk Factors and the Global Burden of Chronic Obstructive Pulmonary Disease. Am J Respir Crit Care Med. 2010 Sep 1; 182(5): 693-718.

10. Deborah Leader. COPD and Women: Exploring Gender Differences in COPD. Available at http://copd.about.com/od/copdbasics/a/Copd-And-Women-The-New-Face-Of-Copd.htm.

Accessed on 02.02.12.

11. Jindal SK, Aggarwal AN, Gupta D. A review of population studies from India to estimate the national burden of chronic obstructive pulmonary disease and its association with smoking. Indian J chest Dis. Allied Sci. 2001; 43(3): 139-47.

12. Mahesh PA, Jayaraj BS, Prahlad ST, Chaya SK, Prabhakar AK, Agarwal AN, Jindal SK. Validation of a structured questionnaire for COPD and prevalence of COPD in rural area of Mysore: a pilot study. Lung India 2009; 26 (3): 63-9.

13. Menezes AM, Perez-Padilla R, PLATINO Team. Chronic obstructive pulmonary disease in five Latin American cities (the PLATINO study): a prevalence study. Lancet 2005 Nov; 366(9500): 1875-81.

14. Jindal SK, Aggarwal AN, Chaudhry K, Chhabra SK, D'Souza GA, Gupta D et al. A multicentric study on epidemiology of Chronic Obstructive Pulmonary Disease and its relationship with tobacco smoking and environmental tobacco smoke exposure. Indian J Chest Dis Allied Sci. 2006 Jan-Mar; 48(1): 23-9.

15. Prescott E, Lange P, Vestbo J, Copenhagen City Heart Study Group. Socioeconomic status, lung function and admission to hospital for COPD: results from the Copenhagen City Heart Study. Eur Respir J 1999; 13: 1109-14.

16. Behera D, Jindal SK. Respiratory symptoms in Indian women using domestic cooking fuels. Chest 1991 Aug; 100(2): 385-8.

17. Qureshi KA. Domestic smoke pollution and prevalence of chronic bronchitis/asthma in a rural area of Kashmir. Indian J Chest Dis Allied Sci 1994; 36:61-72.

18. Chan-Yeung M, Ait-Khaled N, White N, Ip MS, Tan WC. The burden and impact of COPD in Asia and Africa. Int J Tuberc Lung Dis. 2004 Jan; 8(1): 2-14. 


\section{ORIGINAL ARTICLE}

\begin{tabular}{|c|c|c|c|c|c|}
\hline Age Category & $\mathbf{N}$ & $\begin{array}{c}\text { COPD } \\
\text { (\% age in each } \\
\text { category) }\end{array}$ & $\begin{array}{l}\text { Mean FEV } 1 \\
\text { (SD) }\end{array}$ & $\begin{array}{l}\text { Mean FVC } \\
\text { (SD) }\end{array}$ & $\begin{array}{c}\text { Mean FEV } 1 / F V C \\
\text { (SD) }\end{array}$ \\
\hline $35-50$ years & 648 & $12(1.9 \%)$ & $97.44 \pm 13.42$ & $101.94 \pm 18.2$ & $97.19 \pm 13.2$ \\
\hline 50-65 years & 259 & $6(2.3 \%)$ & $98.9 \pm 14.15$ & $104.16 \pm 18.4$ & $96.14 \pm 12.07$ \\
\hline $\begin{array}{c}\text { More than } 65 \\
\text { years }\end{array}$ & 120 & $34(28.3)$ & $89.57 \pm 19.78$ & $103.4 \pm 22.7$ & $87.90 \pm 19.13$ \\
\hline TOTAL & 1027 & $52(5.1 \%)$ & & & \\
\hline \multicolumn{3}{|c|}{ F value (ANOVA) } & $\begin{array}{c}12.363 \\
(\mathrm{df}=431)\end{array}$ & $\begin{array}{c}1.536 \\
(d f=431)\end{array}$ & $\begin{array}{c}15.485 \\
(d f=431)\end{array}$ \\
\hline \multicolumn{3}{|c|}{ p-value } & 0.00 & 0.58 & 0.000 \\
\hline
\end{tabular}

Table I: Distribution of study participants as COPD status stratified by age

$\chi^{2}$ for trend: $99.9, \mathrm{p}$ value: 0.000

\begin{tabular}{|c|c|c|c|c|}
\hline \multicolumn{2}{|r|}{$\mathrm{N}=1027$} & $\mathbf{N}$ & COPD* & Significance \\
\hline \multirow{2}{*}{ Education } & Upto primary level & 577 & $39(6.8 \%)$ & \multirow{2}{*}{$\begin{array}{c}\chi^{2} 7.87 ; \mathrm{df} 1 ; \\
\text { p value: } 0.005\end{array}$} \\
\hline & More than primary level & 450 & $13(2.9 \%)$ & \\
\hline \multirow{4}{*}{$\begin{array}{c}\text { Monthly family } \\
\text { income () }\end{array}$} & Less than $3,000^{\#}$ & 105 & $6(5.7 \%)$ & \multirow{4}{*}{$\begin{array}{l}\chi^{2} 11.91 ; \mathrm{df} 3 ; \\
\text { p value: } 0.008\end{array}$} \\
\hline & $3,000-6,000^{\#}$ & 91 & $11(12.1 \%)$ & \\
\hline & $6,000-12,000^{\#}$ & 799 & $35(4.4 \%)$ & \\
\hline & $>12,000^{\#}$ & 32 & 0 & \\
\hline
\end{tabular}

*(shows percentage within group)

\# Monthly income in Indian rupees

\begin{tabular}{|c|c|c|c|c|}
\hline & Number* & COPD* & \\
\hline \multirow{2}{*}{$\begin{array}{c}\text { Kitchen Smoke } \\
\text { Exposure }\end{array}$} & $\begin{array}{c}\text { Light exposure } \\
\text { (Kitchen exposure }<20 \\
\text { years) }\end{array}$ & $\begin{array}{c}271 \\
(26.4 \%)\end{array}$ & $8(3.0 \%)$ & \\
\cline { 2 - 4 } & $\begin{array}{c}\text { Moderate exposure } \\
\text { (Kitchen exposure 20-30 } \\
\text { years) }\end{array}$ & $\begin{array}{c}416 \\
(40.5 \%)\end{array}$ & \multirow{2}{*}{$16(3.8 \%)$} & $\begin{array}{c}\chi^{2} \text { trend 9.339; } \\
\text { p value: } 0.002\end{array}$ \\
\cline { 2 - 4 } & $\begin{array}{c}\text { Heavy exposure } \\
\text { (Kitchen exposure }>30 \\
\text { years) }\end{array}$ & $\begin{array}{c}340 \\
(33.1 \%)\end{array}$ & $28(8.2 \%)$ & \\
\hline
\end{tabular}


ORIGINAL ARTICLE

\begin{tabular}{|c|c|c|c|c|}
\hline \multirow{3}{*}{ Smoking status } & Ever smoker & $36(3.5 \%)$ & $9(25 \%)$ & \multirow{2}{*}{$\begin{array}{c}\text { (OR } 7.35 ; 95 \% \text { CI } \\
3.25-16.6)\end{array}$} \\
\hline & Non smoker & $\begin{array}{c}991 \\
(96.5 \%)\end{array}$ & $43(4.3 \%)$ & \\
\hline & TOTAL & 1027 & $52(5.1 \%)$ & \\
\hline
\end{tabular}

*(shows percentage within group)

\begin{tabular}{|c|c|c|}
\hline \multirow{2}{*}{ Parameter } & \multicolumn{2}{|c|}{ Odds ratio ( $95 \%$ confidence interval) } \\
\hline & Multivariate analysis & P value \\
\hline Age more than 50 years & $\begin{array}{c}13.140 \\
(5.64-23.095)\end{array}$ & 0.000 \\
\hline Age Less than 50 years & 1.000 & - \\
\hline Monthly family Income Less than 6000 & $\begin{array}{c}3.11 \\
(1.547-6.25)\end{array}$ & 0.001 \\
\hline Monthly family Income more than 6000 & 1.000 & - \\
\hline Education only upto primary level & $\begin{array}{c}1.74 \\
(0.841-3.732)\end{array}$ & 0.149 \\
\hline Higher than primary education & 1.000 & - \\
\hline Ever Smoker & $\begin{array}{c}6.187 \\
(2.274-16.836)\end{array}$ & 0.003 \\
\hline Never smoker & 1.000 & - \\
\hline Use of Biomass fuel & $\begin{array}{c}1.46 \\
(1.087-3.248)\end{array}$ & 0.04 \\
\hline Coal Heating & $\begin{array}{c}2.65 \\
(0.861-4.763) \\
\end{array}$ & 0.27 \\
\hline Use of LPG & 1.000 & - \\
\hline Location of kitchen inside house & $\begin{array}{c}2.013 \\
(1.176-3.821)\end{array}$ & 0.035 \\
\hline Location of kitchen outside house & 1.000 & - \\
\hline Kitchen fuel Exposure more than 30 years & $\begin{array}{c}2.479 \\
(1.414-4.374) \\
\end{array}$ & 0.001 \\
\hline Kitchen fuel Exposure more than 30 years & 1.000 & - \\
\hline
\end{tabular}




\section{ORIGINAL ARTICLE}

\section{AUTHORS:}

1. Mukhmohit S.

2. Bhardwaj A.

3. Saini S.

4. Mukherjee A. K.

5. Kannan R.

\section{PARTICULARS OF CONTRIBUTORS:}

1. Assistant Professor, Department of Community Medicine, MMIMSR, Mullana, Ambala, Haryana.

2. Assistant Professor, Department of Community Medicine, MMIMSR, Haryana, India.

3. Assistant Professor, Department of Community Medicine, SIMSRC, Bangalore, India.
4. Professor, Department of Community Medicine, MMIMSR, Haryana, India.

5. PG Resident, Department of Community Medicine, Chettinad Hospital and Research Institute, Chennai, India.

\section{NAME ADDRESS EMAIL ID OF THE}

\section{CORRESPONDING AUTHOR:}

Dr. Mukhmohit Singh,

\# 936, Sector 2,

Panchkula, Haryana.

E-mail: mukhmohit5@yahoo.com

Date of Submission: 17/01/2014.

Date of Peer Review: 18/01/2014.

Date of Acceptance: 07/03/2014.

Date of Publishing: 16/03/2014. 